\title{
Screening of Alkaloid-Producing Endophytic Penicillium Strains from Amazon Medicinal Plants by Electrospray Ionization Mass Spectrometry (ESI-MS) and Principal Component Analysis (PCA)
}

\author{
Francinaldo A. da Silva-Filho, ${ }^{a}$ Marjory M. M. de Souza, ${ }^{b}$ Gabriel O. Rezende, ${ }^{b}$ \\ Felipe M. A. da Silva, ${ }^{\circledR}$ Jeferson C. da Cruz, ${ }^{\circledR}{ }^{\circ}$ Gilvan F. da Silva, ${ }^{\circledR d}$ \\ Afonso D. L. de Souza ${ }^{\circledR a, c, e}$ and Antonia Q. L. de Souza ${ }^{\circledR *, a, b, c, f}$ \\ aPrograma de Pós-Graduação da Rede Bionorte, Universidade Federal do Amazonas (UFAM), \\ 69077-000 Manaus-AM, Brazil

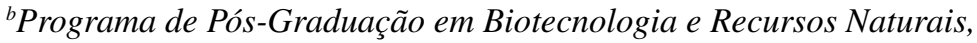 \\ Escola Superior de Ciências da Saúde, Universidade do Estado do Amazonas (UEA), \\ 69000-000 Manaus-AM, Brazil \\ ${ }^{c}$ Central Analítica-Centro de Apoio Multidisciplinar (CAM), \\ Universidade Federal do Amazonas (UFAM), 69077-000 Manaus-AM, Brazil \\ ${ }^{d}$ Embrapa Amazônia Ocidental, 69010-970 Manaus-AM, Brazil \\ eDepartamento de Química (ICE), Universidade Federal do Amazonas (UFAM), \\ 69077-000 Manaus-AM, Brazil

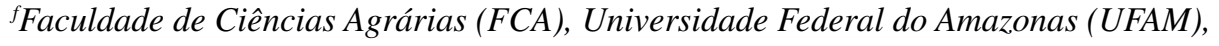 \\ 69077-000 Manaus-AM, Brazil
}

\begin{abstract}
The genus Penicillium is among the most promising alkaloid-producing fungal and therefore plays an important role in terms of producing molecules with biotechnological potential. Thus, in order to identify alkaloid-producing fungi, 25 endophytic Penicillium strains previously isolated from Amazon medicinal plants were subject to an integrative approach based on direct infusion positive electrospray ionization mass spectrometry (ESI-MS) and principal component analysis (PCA). The multivariate analysis pointed paxiline $(\mathbf{1})$, glandicoline B (2), roquefortine $\mathrm{C}(\mathbf{3})$, and oxaline (5) as responsible for the segregation of three promising alkaloid-producing groups, been these groups constituted for $P$. chrysogenum, $P$. oxalicum, $P$. paxilli, and $P$. rubens strains. These alkaloids and the glandicoline A (4) were tentatively identified by multiple-stage mass spectrometry. In addition, compounds $\mathbf{1}$ and $\mathbf{2}$ were isolated and confirmed by using 1D and 2D nuclear magnetic resonance (NMR) spectroscopy. Overall, the chemical profile analysis by ESI-MS along with PCA provided a simple and effective approach to screening alkaloid-producing Penicillium strains for biotechnological applications.
\end{abstract}

Keywords: glandicoline, paxilline, Penicillium oxalicum, Penicillium paxilli, Penicillium rubens, oxaline

\section{Introduction}

Fungi are widely distributed throughout the planet integrating the biogeological cycles of all ecosystems. ${ }^{1}$ They comprise a wide variety of species, around 3.8 million, distributed mainly on environments such as in soil, water, and associated with plants and others

*e-mail: antoniaqueiroz@ufam.edu.br organisms. ${ }^{2}$ When associated with plants they are known as endophytics, and live in the inter and intracellular spaces of this individual for at least a period of their life cycle. ${ }^{3}$ Usually, they have a symbiotic association with the plants that protect and provide nutrients to the endophyte, which, in turn, benefit the host through the control of pathogens as well as in the absorption of nutrients and the production of phytohormones. ${ }^{4}$ Thus, endophytes not only provide advantages to the host but 
also are sources of new metabolites with diverse biological activities. ${ }^{5}$ Among these endophytes, some genus as Aspergillus, Trichoderma, Fusarium, and Penicillium stand out in terms of producing molecules with several biotechnological potentials, such as antibiotics, antioxidants, and antitumoral agents. ${ }^{6-9}$

Since the discovery of the penicillin in 1929 , the genus Penicillium, which is composed by approximately 354 known species, ${ }^{10}$ has been described as a promising source of bioactive compounds, such as polyphenols, polyketides, and alkaloids. ${ }^{11-13}$ Alkaloids produced by Penicillium has been showed potential to biotechnological applications, been their antimicrobial, antiviral, and anticancer activities previously described. ${ }^{14-18}$

The prospection of bioactive compounds or new molecules from microorganisms is an important and complex task, which usually demands modern analytical techniques with high sensitivity and selectivity, such as that based on mass spectrometry (MS). ${ }^{19,20}$ In the recent years, these mass spectrometry-based approaches has been proved to be a powerful strategy for the screening and identification of bioactive compounds in plant and microorganism species as well as to chemotaxonomic approaches, when combined with chemometric tools. ${ }^{21-23}$ Thus, in this study, 25 endophytic Penicillium strains previously isolated from Amazon medicinal plants were screened for alkaloid-producing by an integrative approach based on direct infusion positive electrospray ionization mass spectrometry (ESI-MS) and principal component analysis (PCA).

\section{Experimental}

\section{Fungal cultivation and micro-scale metabolites} extraction

The 25 strains previously isolated from Brazilian medicinal plants are deposited in the work collection of the Amazon Bioassay and Microorganism Laboratory from Amazon Federal University (LabMicra/UFAM) and has the access to genetic heritage registered at Sistema Nacional de Gestão do Patrimônio Genético e do Conhecimento Tradicional Associado (SisGen) under the code No. AD64E07 (Table 1). They were grown in Petri dishes containing ISP2 medium ( $10 \mathrm{~g}$ corn starch, $4 \mathrm{~g}$ yeast extract, $10 \mathrm{~g}$ malt, $4 \mathrm{~g}$ dextrose, and $20 \mathrm{~g}$ agar for every $1 \mathrm{~L}$ of distilled water) for 10 days at $26^{\circ} \mathrm{C}$.

After the cultivation period, three plugs of $6 \mathrm{~mm}$ diameter were removed from each plate and transferred to $5 \mathrm{~cm}$ test tubes and extracted for $24 \mathrm{~h}$ with $2 \mathrm{~mL}$ of a solution containing 3:2:1 ethyl acetate/dichloromethane/ methanol, with $1 \%$ formic acid. ${ }^{24}$ The solvent was then
Table 1. Endophytic Penicillium strains subjected to alkaloidal screening

\begin{tabular}{|c|c|c|c|}
\hline Strain ID & $\begin{array}{l}\text { ID in the work } \\
\text { collection }\end{array}$ & Host (plant) & Part of the plant \\
\hline A & GhcR3 2.2 (401) & Gustavia elliptica & root bark \\
\hline B & PbR2 2.2 (135) & Mauritia flexиosa & root \\
\hline $\mathrm{C}$ & GhcR1 1.1a (415) & G. elliptica & root bark \\
\hline $\mathrm{D}$ & GhcC1 1.2c (414) & G. elliptica & stem bark \\
\hline $\mathrm{E}$ & StspC2 1.2c (180) & Strychnos sp. & stem \\
\hline $\mathrm{F}$ & GhR1 2.1 (391) & G. elliptica & root \\
\hline G & $\operatorname{VrF1} 2.2(64)$ & Victoria amazonica & leaf \\
\hline $\mathrm{H}$ & AspC2 2.2 (52) & Annona sp. & stem \\
\hline I & AnspG1 2.2 (56) & Annona sp. & twig \\
\hline $\mathrm{J}$ & GhcR1 1.1b (433) & G. elliptica & root bark \\
\hline K & AnspG1 2.3b (155) & Annona sp. & twig \\
\hline $\mathrm{L}$ & $V r F 22.3$ (149) & V. amazonica & leaf \\
\hline M & $\operatorname{VrC2} 2.1 c(143)$ & V. amazonica & stem \\
\hline $\mathrm{N}$ & GhG2 2.1 (392) & G. elliptica & twig \\
\hline $\mathrm{O}$ & AnspG1 2.3a (153) & Annona sp. & twig \\
\hline$P$ & AnspC2 3.1 (38) & Annona sp. & stem \\
\hline Q & GhR1 2.1a (396) & G. elliptica & root \\
\hline $\mathrm{R}$ & GhcG3 2.2 (457) & G. elliptica & twig bark \\
\hline S & GhR2 1.2b (408) & G. elliptica & root \\
\hline $\mathrm{T}$ & $\operatorname{VrC2} 1.2(71)$ & V. amazonica & stem \\
\hline $\mathrm{U}$ & AnspcG1 3.3 (48) & Annona sp. & twig bark \\
\hline V & GhcR3 2.2 (403) & G. elliptica & root bark \\
\hline W & $G h G 32.2 c(407)$ & G. elliptica & twig \\
\hline$X$ & $E j C 32.1 a(307)$ & Piper peltata & stem \\
\hline $\mathrm{Y}$ & $G h c C 22.2 a(409)$ & G. elliptica & stem bark \\
\hline
\end{tabular}

filtered through a small piece of cotton and concentrated, yielding around $1 \mathrm{mg}$ of extract in general for all samples.

Fungal cultivation and large-scale metabolites extraction

For the fungal metabolic production, two strains with even peaks in their mass-spectra profiles, $P$. paxilli $(\mathrm{O})$ and $P$. rubens $(\mathrm{V})$, were cultivated in preparative scale, using 60 Erlenmeyer flasks of $1 \mathrm{~L}$ containing $300 \mathrm{~mL}$ of ISP2 liquid medium each. The cultivation was made at $26{ }^{\circ} \mathrm{C}$ in static mode for 23 days. $\mathrm{pH}$ and glucose were measured in the beginning of the cultivation and in the end. After the cultivation period, the crude fermentation broth was separated from the mycelium by vacuum filtration. Extraction of the fermentation broth $(18 \mathrm{~L})$ was performed with ethyl acetate $(3 \times 500 \mathrm{~mL}),{ }^{25}$ providing the organic phase that was concentrated, yielding $1.3 \mathrm{~g}$ of crude extract for the P. paxilli and $1.9 \mathrm{~g}$ for the $P$. rubens. Both extracts were stored at $4{ }^{\circ} \mathrm{C}$. 


\section{ESI-MS and PCA analysis}

The micro-scale extracts were resuspended in methanol (HPLC grade), creating the stock solutions $\left(1 \mathrm{mg} \mathrm{mL}^{-1}\right)$. Aliquots $(5 \mu \mathrm{L})$ of the stock solutions were further diluted to $5 \mu \mathrm{g} \mathrm{mL}^{-1}$ and analyzed by direct infusion into the mass spectrometers. An ion-trap mass spectrometer, model LCQ Fleet (Thermo Scientific, San Jose, CA, USA), equipped with electrospray ionization (ESI) interface and running in the positive ion mode was used to perform ESI-MS and a triple quadrupole mass spectrometer, model TSQ Quantum Access (Thermo Scientific, San Jose, CA, USA) to perform ESI-MS/MS analyses. Samples were directly infused into the ion source through the instrument syringe pump $\left(10 \mu \mathrm{L} \mathrm{min}{ }^{-1}\right)$. MS analytical conditions: spray voltage, $5 \mathrm{kV}$; sheath gas, 10 arbitrary unit (arb); auxiliary gas, 5 arb; sweep gas, 0 arb; capillary temp, $200^{\circ} \mathrm{C}$; capillary voltage, $40 \mathrm{~V}$; tube lens, $115 \mathrm{~V}$; mass range, $m / z 150$ to 1000 . Argon was used as collision gas, and the ESI-MS/MS spectra were obtained using collision energies ranging from 25 to $30 \mathrm{eV}$. For the principal component analysis (PCA), initially, the relative ion intensity obtained by ESI-MS from $\mathrm{m} / \mathrm{z}, 150$ to 1000 (850 variables) was analyzed through Chemoface ${ }^{\mathrm{TM}}$ program. ${ }^{21,22,26}$ In order to highlight only the alkaloid-producing strains groups, a new PCA analysis was performed based only in the relative intensity of even ions (426 variables).

\section{Alkaloids isolation}

P. paxilli crude extract ( $1.3 \mathrm{~g})$ was subjected to silica gel column chromatography (CC) with increasing gradient of polarity: hexane-ethyl acetate (70:30, 30:70, and 0:100, v/v), ethyl acetate-methanol (80:20 and $0: 100, \mathrm{v} / \mathrm{v})$, affording 5 fractions ( $50 \mathrm{~mL}$ each). Fraction 2 (PP.F2) (97 mg) was subjected to C18 CC eluted with water-methanol $(50: 50$ to $0: 100, \mathrm{v} / \mathrm{v})$, giving 5 fractions (50 mL each). Then, the fractions 3 (PP.F2.3, $18 \mathrm{mg}$ ) and 4 (PP.F2.4, $10 \mathrm{mg}$ ) were pooled into a new fraction (PP.F2.3-4, $28 \mathrm{mg}$ ) according to MS analysis. PP.F2.3-4 was submitted to a semi-preparative Shimadzu highperformance liquid chromatography (HPLC), model UFLC (Shimadzu, Columbia, MD, USA), using water (A) and methanol (B) as mobile phases. The gradient elution was as follows: $0-10 \mathrm{~min}, 70-100 \% \mathrm{~B}(\mathrm{v} / \mathrm{v})$ and $10-25 \mathrm{~min}$, $100 \% \mathrm{~B}$ at a flow rate of $3.4 \mathrm{~mL} \mathrm{~min}^{-1}$. A C18 column $(250 \times 10 \mathrm{~mm}, 5 \mathrm{~m})$ was employed on the fractionation and the UV channels at 280 and $232 \mathrm{~nm}$ were monitored. A single injection was carried onto the column in dimethyl sulfoxide (DMSO, $150 \mu \mathrm{L}$ ), yielding compound $1(13 \mathrm{mg}$ ) as an amorphous white solid.
Similarly, P. rubens crude extract $(1.9 \mathrm{~g})$ was subjected to $\mathrm{C} 18 \mathrm{CC}$ eluted with water-methanol (70:30, 30:70, and $0: 100, \mathrm{v} / \mathrm{v})$, affording 3 fractions $(50 \mathrm{~mL}$ each). Fraction 2 (PR.F2) (470 mg) was subjected to $\mathrm{C} 18 \mathrm{CC}$ and eluted with water-methanol (60:40, 40:60, and 0:100, $\mathrm{v} / \mathrm{v})$, giving 3 fractions (50 $\mathrm{mL}$ each). Then, fraction 2 (PR.F2-2) $(80 \mathrm{mg}$ ) was subjected to over $\mathrm{C} 18 \mathrm{CC}$ and eluted with water-methanol (50:50 and 0:100, v/v), giving 2 fractions (50 mL each). Finally, fraction 1 (PR.F2-2-1) $(30 \mathrm{mg})$ was submitted to a semi-preparative HPLC, model UFLC (Shimadzu, Columbia, MD, USA), using water (A) and methanol (B) as mobile phases. The gradient elution was as follows: 0-45 min, 45-59\% B (v/v), 45-50 min, $59-100 \% \mathrm{~B}(\mathrm{v} / \mathrm{v})$, and $50-70 \mathrm{~min}, 100 \% \mathrm{~B}(\mathrm{v} / \mathrm{v})$ at a flow rate of $3.4 \mathrm{~mL} \mathrm{~min}^{-1}$. The same $\mathrm{C} 18$ column above was employed on the fractionation and the UV channels at 240 and $300 \mathrm{~nm}$ were monitored. A single injection was carried onto the column in DMSO $(150 \mu \mathrm{L})$, which afforded compound $2(5 \mathrm{mg})$ as an amorphous yellow solid.

\section{NMR analysis}

The one-dimensional (1D) and two-dimensional (2D) nuclear magnetic resonance (NMR) analysis were performed with an AVANCE III HD 500 NMR spectrometer (Bruker, Billerica, MA, USA), operating at $11.75 \mathrm{~T}$, observing ${ }^{1} \mathrm{H}$ at 500.13 and ${ }^{13} \mathrm{C}$ at $125.76 \mathrm{MHz}$. Deuterated methanol (MeOD) (Cambridge Isotope, Tewksbury, MA, USA) was used as solvent. All chemical shifts $(\delta)$ are given in ppm relative to the solvent signal, and the coupling constants $(J)$ are given in $\mathrm{Hz}$.

\section{Microorganism identification}

The identification of the alkaloid-producing Penicillium strains was confirmed by sequencing of the fungus internal transcribed space-1 (ITS) and ITS-2 rDNA and compared with sequences from the GenBank. $10 \mu \mathrm{L}$ of the strains spore suspension concentrated in $30 \times 10^{8}$ cells $\mathrm{mL}^{-1}$ was incubated on $50 \mathrm{~mL}$ potato dextrose (PD), medium in a $125 \mathrm{~mL}$ Erlenmeyer and stirred for $36 \mathrm{~h}(120 \mathrm{rpm})$ at $26^{\circ} \mathrm{C}$ temperature. The mycelium was separated from the medium by filtration and crushed with silica gel and then preceded to extraction. The total deoxyribonucleic acid (DNA) was extracted by a Zymo Research Quick-DNA ${ }^{\mathrm{TM}}$ Fungal/ Bacterial Miniprep Kit using its own protocol with some adaptations, using $50 \mu \mathrm{L}$ of the DNA dilution buffer instead of protocol's $100 \mu \mathrm{L}$ and using longer centrifugation times on all steps. After the extraction, the DNA was sequenced using a model 3500 Genetic Analyzer (Applied Biosystems, Foster city, CA, USA). All the data was then analyzed 
Table 2. Species identification of nine Penicillium endophytic strains by molecular approach with NCBI's BLASTn information

\begin{tabular}{|c|c|c|c|c|c|c|c|}
\hline Strain ID & Group & Description & Max score & Total score & Query cover / \% & Expect value & Percent identity / \% \\
\hline$\overline{\mathrm{H}}$ & $\mathrm{I}$ & P. paxilli & 990 & 1165 & 99 & 0 & 100.00 \\
\hline $\mathrm{O}$ & I & P. paxilli & 979 & 979 & 100 & 0 & 100.00 \\
\hline $\mathrm{X}$ & I & P. paxilli & 924 & 924 & 98 & 0 & 99.22 \\
\hline B & III & P. chrysogenum & 977 & 1082 & 100 & 0 & 100.00 \\
\hline V & III & P. rubens & 1195 & 1517 & 100 & 0 & 98.12 \\
\hline $\mathrm{N}$ & III & P. rubens & 1042 & 1042 & 99 & 0 & 100.00 \\
\hline G & IV & P. oxalicum & 761 & 761 & 100 & 0 & 98.61 \\
\hline $\mathrm{L}$ & IV & P. oxalicum & 911 & 911 & 99 & 0 & 99.80 \\
\hline M & IV & P. oxalicum & 979 & 979 & 100 & 0 & 100.00 \\
\hline $\mathrm{T}$ & IV & P. oxalicum & 952 & 952 & 98 & 0 & 99.81 \\
\hline
\end{tabular}

and processed using National Center for Biotechnology Information's (NCBI) Nucleotide Basic Local Alignment Search Tool (BLASTn) tool (Table 2).

\section{Results and Discussion}

The direct infusion ESI positive mass spectra of the Penicillium strains crude extracts from $\mathrm{m} / \mathrm{z} 150$ to 1000 displayed several base peak ions in the range of $400-800 \mathrm{Da}$ (Figures S1 to S25, Supplementary Information (SI) section), such as $m / z 420,448$, and 458 , suggesting the presence of alkaloids in a large portion of the samples. This proposal was based on previous studies with fungal alkaloids containing an odd number of nitrogen atoms, such as indole alkaloids, where protonation process provides products with even $\mathrm{m} / \mathrm{z}$ values. ${ }^{23,27,28}$ Besides base peak, several other ions were observed, indicating these samples as complex matrixes. In the first PCA score plot (Figure 1a), based on the relative intensity of $\mathrm{m} / \mathrm{z} 150$ to 1000 (850 variables), five main groups (group I-V) were observed, being group I formed by three strains, group II by eight strains, group III by three strains, group IV by four strains and group V by seven strains. On the other hand, the second PCA score plot (Figure 1b), based on only the relative intensity of even ions (426 variables), highlighted the groups I, III, and IV as discrete alkaloid-producing groups. The groups II and V became together in this graph, reveling to be similar in the production of alkaloids. In fact, the strains of these groups have shown low intense even ions, reveling to be poor alkaloid producers, at least in the grown conditions used.

According to the PCA biplot $(\mathrm{PC} 2 \times \mathrm{PC} 3)$ of scores and loadings (Figure 1c), the ions at $\mathrm{m} / \mathrm{z} 390,420,448$, and 458 were the main responsible for the segregation of the groups I, III, and IV. The MS/MS spectra of some of these ions (Figure 2) revealed key fragmentations (losses of 68 or $69 \mathrm{Da}$ ) previously described for prenylated alkaloids, such as roquefortine and related compounds. ${ }^{17,27}$
The MS/MS spectrum of the ion at $\mathrm{m} / \mathrm{z} 390$ (Figure 2a) displayed, besides the initial loss of the prenyl group $(-68 \mathrm{Da}, \mathrm{m} / \mathrm{z} 390 \rightarrow 322$ ), a base peak at $\mathrm{m} / \mathrm{z}$ 193, which is in accordance with the structure of roquefortine $\mathrm{C} \mathrm{(3)}$ (Figure 3). ${ }^{27}$ The MS/MS spectrum of the ion at $m / z 420$ (Figure 2b) also displayed the initial loss of the prenyl group $(-69 \mathrm{Da}, \mathrm{m} / z, 420 \rightarrow 351)$, as well as a base peak at $\mathrm{m} / \mathrm{z} 289$, being this fragmentation consistent with the structure of glandicoline B (2) (Figure 3). ${ }^{17}$ Moreover, the MS/MS spectrum of the ion at $\mathrm{m} / \mathrm{z} 448$ (Figure 2c) displayed an initial loss of a methoxyl group ( $-31 \mathrm{Da}$, $m / z, 448 \rightarrow 417)$, followed by a loss of a prenyl group (-69 Da, $417 \rightarrow 348$ ), which is in accordance with the structure of the alkaloid oxaline (5) (Figure 3) ${ }^{23}$ On the other hand, the MS/MS spectrum of the ion at $\mathrm{m} / \mathrm{z} 458$ do not generate fragments, even increasing the collision energy. Since this phenomenon is recurrent for sodium adduct molecular ions, ${ }^{28}$ the sodium mass was taken into consideration, and the correspondent protonated ion at $\mathrm{m} / z 436$ was submitted to MS/MS analysis. Thus, the MS/MS spectrum of the ion at $\mathrm{m} / \mathrm{z} 436$ (Figure 2d) presented a base peak at $m / z 130$ and a less intense ion at $\mathrm{m} / \mathrm{z}$ 182 , being this fragmentation consistent with the structure of paxilline (1) (Figure 3). ${ }^{28}$ Paxilline (1), as well as glandicoline B (2), were also confirmed by a comparison of their NMR data (SI section, Figures S32 to S39, Tables S1 and S2) with those reported in the literature. ${ }^{17,29,30}$

Besides, after a manual inspection of the MS spectra from group III, a minor ion at $\mathrm{m} / \mathrm{z} 404$ was tentatively identified as glandicoline A (4), the precursor of the glandicoline B. Thus, the MS/MS spectrum of 4 (Figure 2e) presented a loss of prenyl group ( $-69 \mathrm{Da}, \mathrm{m} / z, 404 \rightarrow 335$ ) as well as the base peak at $m / z 319$, in coherence with the structure of glandicoline A. ${ }^{27}$

Since the alkaloids $\mathbf{1 - 5}$ were tentatively identified between strains from the groups I ( $\mathrm{H}, \mathrm{O}$, and $\mathrm{X})$, III (B, $\mathrm{N}$, and $\mathrm{V}$ ), and IV (G, L, M, and T), these organisms were assigned as alkaloid-producing strains and identified 

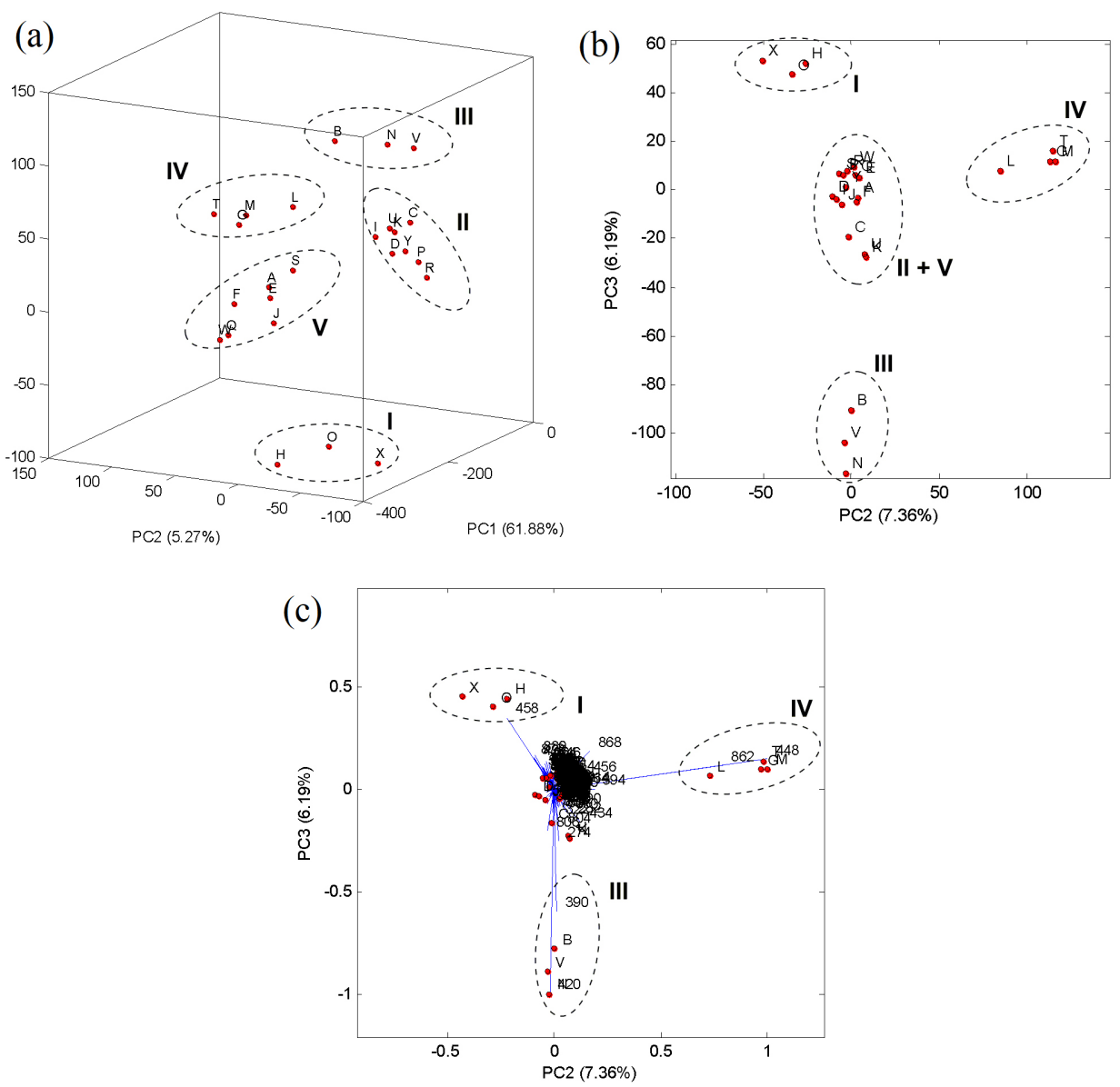

Figure 1. PCA score plots ( $\mathrm{a}$ and $\mathrm{b}$ ) and biplot of scores and loadings (c) generated from the crude extract ESI-MS data from twenty-five endophytic Penicillium strains from Amazon medicinal plants (A-Y).

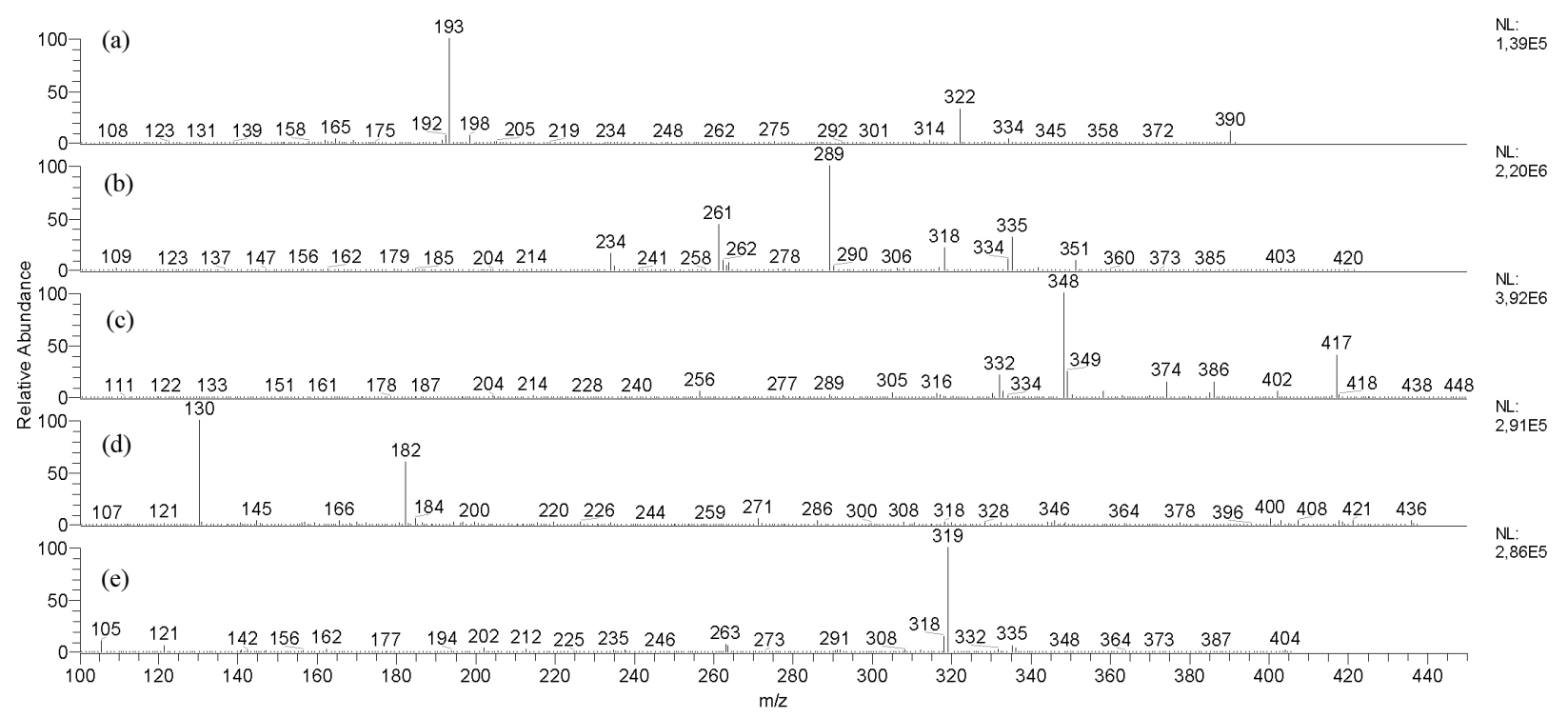

Figure 2. ESI-MS/MS spectra (positive mode) of the ion at $\mathrm{m} / \mathrm{z} 390$ (a), 420 (b), 448 (c), 436 (d), and 404 (e), present in the crude extracts of Penicillium strains.

by molecular approach (Table 2). Using the BLASTn it was possible to identify the strains $\mathrm{H}, \mathrm{O}$, and $\mathrm{X}$ of the group I as P. paxilli, a fungus known to produce indole diterpene alkaloids, such as paspaline, paxilline (1) and derivates. ${ }^{29,31}$ Likewise, the strain B, from the group III, was identified as $P$. chrysogenum, while the strains $\mathrm{N}$ 


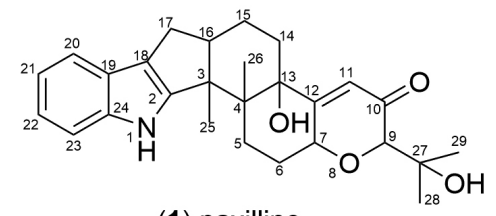

(1) paxilline

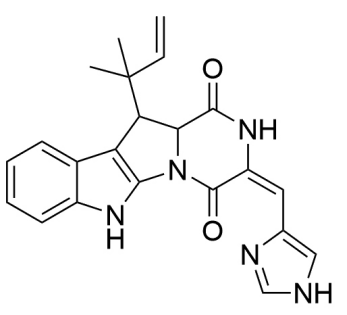

(3) roquefortine $\mathrm{C}$

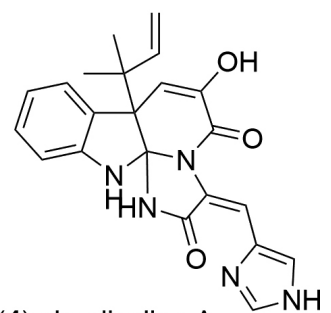

(4) glandicoline A
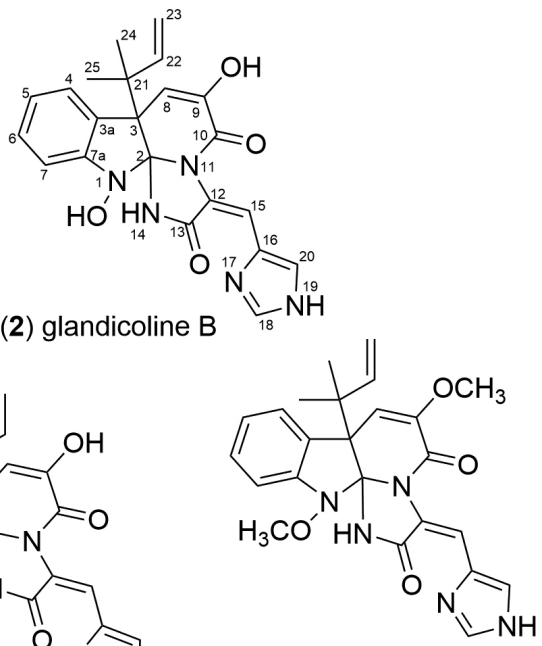

(5) oxaline

Figure 3. Isolated and identified compounds from the Penicillium strains present in groups I (1), III (2-4) and IV (5).

and $\mathrm{V}$ were identified as $P$. rubens. These two fungal species are genetically and chemically close, and has been described as promising sources of diketopiperazine alkaloids, such as roquefortines (2-4) and other alkaloids with biotechnological potential..$^{32}$ By its turn, the strains $\mathrm{G}, \mathrm{L}, \mathrm{M}$, and $\mathrm{T}$ of the group IV were identified as $P$. oxalicum, which is also known to produce roquefortine alkaloids, however towards the end of the pathway such as meleagrin and oxaline (5) ${ }^{33}$ These observations suggest a close biosynthetic relationship between the strains from the groups III and IV. Surprisingly, all species from the group IV were isolated from the same host (V. amazonica), suggesting that the host can play a role in the metabolites production or the selection of its fungi community.

Paxilline is a indole diterpene alkaloid firstly described in P. paxilli, ${ }^{29}$ and also found in $P$. tularense, Acremonium lorii, Emericella desertorum, E. foveolata, and E. striata. ${ }^{34,35} \mathrm{It}$ is known to have tremorgenic, anticonvulsant and antiinsectan activity. ${ }^{36-38}$ Paxilline is also a calcium-activated $\mathrm{K}^{+}$channel blocker (BK), that has showed to attenuate thalidomidecaused synaptic and cognitive dysfunctions in mice. ${ }^{39} \mathrm{On}$ the other hand, glandicoline B is an important intermediate of the roquefortine-oxaline biosynthetic pathway. ${ }^{33}$ Glandicoline B is a precursor of the diasteromeric pair oxaline (5) and neoxaline, both with anticancer activities against leukemic Jurkat cells through the inhibition of cell proliferation and arrest the cell cycle at the G2/M phase. ${ }^{40}$ Glandicoline B was first described in P. glandicola ${ }^{41}$ and was later reported in $P$. hirsutum, $P$. alli, $P$. radiocolor, $P$. tulipae, and $P$. chrysogenum. ${ }^{42,43}$ On the other hand, roquefortine $\mathrm{C}(\mathbf{3})$ is a relatively common fungal metabolite and has been reported in at least 30 fungal strains, being first reported in a strain of $P$. roquefortii. ${ }^{44-46} \mathrm{It}$ is considered as one of the most common fungal contaminants of cheese, beverages and meats. ${ }^{47}$ Although it is considered a toxin, at low concentrations it was found to be safe for human consumption..$^{48}$ Moreover, roquefortine $\mathrm{C}$ possesses neurotoxic and antimicrobial activities, most likely through inactivation of cytochrome $\mathrm{P} 450 \mathrm{~s} \mathrm{~s}^{49,50}$ The isolated compounds were characterized by ${ }^{1} \mathrm{H}$ and ${ }^{13} \mathrm{C}$ NMR and the data are presented in the SI section (Figures S32 to S39), including the NMR assignments (Tables S1 and S2).

\section{Conclusions}

The present work demonstrated the potential of several endophytic Penicillium strains from Amazon medicinal plants as alkaloid producers, including $P$. chrysogenum, $P$. paxilli, $P$. rubens, and $P$. oxalicum. Moreover, the proposed approach based on the chemical profile by ESI-MS in combination with PCA analysis provided a simple and effective strategy for discriminate Penicillium strains able to produce different types of alkaloids with biotechnological potential.

\section{Supplementary Information}

Supplementary information, including the ${ }^{1} \mathrm{H}$ and ${ }^{13} \mathrm{C}$ NMR data for the isolated compounds (MS and NMR data, Figures $\mathrm{S} 1$ to $\mathrm{S} 39$, NMR assignments (Tables $\mathrm{S} 1$ and $\mathrm{S} 2$ )) is available free of charge at http://jbcs.sbq.org.br as PDF file.

\section{Acknowledgments}

The authors are grateful to Central Analítica (UFAM) for MS and NMR analysis, and Coordenação 
de Aperfeiçoamento de Pessoal de Nível Superior (CAPES) (Finance Code 001), Conselho Nacional de Desenvolvimento Científico e Tecnológico (CNPQ), Financiadora de Estudos e Projetos (FINEP) and Fundação de Amparo à Pesquisa do Estado do Amazonas (FAPEAM) for financial support.

\section{Author Contributions}

Francinaldo A. da Silva-Filho was responsible for the conceptualization, data curation, formal analysis, methodology, and writing original draft and writingreview and editing; Felipe M. A. da Silva for the formal analysis, methodology, writing original draft and writingreview and editing; Marjory M. M. de Souza, Gabriel O. Rezende, Jeferson C. da Cruz and Gilvan F. da Silva for the formal analysis and methodology; Antonia Q. L. de Souza and Afonso D. L. de Souza were responsible for the conceptualization, formal analysis, funding acquisition, methodology, supervision, writing original draft, and writing-review and editing.

\section{References}

1. Branco, S.; Fungal Biol. Rev. 2019, 33, 225.

2. Hawksworth, D. L.; Lucking, R.; Microbiol. Spectrum 2017, 5,1 .

3. Borges, W.; Borges, K.; Bonato, P.; Said, S.; Pupo, M.; Curr. Org. Chem. 2009, 13, 1137.

4. Mane, R. S.; Vedamurthy, A. B.; Int. J. Second. Metab. 2018, $5,288$.

5. Suryanarayanan, T.; Kavaka 2017, 48, 1.

6. Newman, D. J.; Cragg, G. M.; J. Nat. Prod. 2016, 79, 629.

7. Aly, A. H.; Debbab, A.; Kjer, J.; Proksch, P.; Fungal Divers. 2010, 41,1 .

8. Du, L.; Feng, T.; Zhao, B.; Li, D.; Cai, S.; Zhu, T.; Wang, F.; Xiao, X.; Gu, Q.; J. Antibiot. 2010, 63, 165.

9. Gunatilaka, A. A. A. L.; J. Nat. Prod. 2006, 69, 509.

10. Visagie, C. M.; Houbraken, J.; Frisvad, J. C.; Hong, S. B.; Klaassen, C. H. W.; Perrone, G.; Seifert, K. A.; Varga, J.; Yaguchi, T.; Samson, R.; Stud. Mycol. 2014, 78, 343.

11. Lu, Z.; Zhu, H.; Fu, P.; Wang, Y.; Zhang, Z.; Lin, H.; Liu, P.; Zhuang, Y.; Hong, K.; Zhu, W.; J. Nat. Prod. 2010, 73, 911.

12. Marinho, A. M. R.; Rodrigues-Filho, E.; Moitinho, M. L. R.; Santos, L. S.; J. Braz. Chem. Soc. 2005, 16, 280.

13. Bringmann, G.; Lang, G.; Gulder, T. A. M.; Tsuruta, H.; Muhlbacher, J.; Maksimenka, K.; Steffens, S.; Schaumann, K.; Stohr, R.; Wiese, J.; Imhoff, J. F.; Perovic-Ottstadt, S.; Boreiko, O.; Muller, W. E. G.; Tetrahedron 2005, 61, 7252.

14. Hawas, U. W.; Abou El-Kassem, L. T.; Lett. Org. Chem. 2019 , 16, 409.
15. Hayashi, H.; Takiuchi, K.; Murao, S.; Arai, M.; Agric. Biol. Chem. 1989, 53, 461.

16. Kusano, M.; Koshino, H.; Uzawa, S.; Kawano, T.; Kimura, Y.; Biosci., Biotechnol., Biochem. 2000, 64, 2559.

17. Koolen, H. H. F.; Soares, E. R.; Silva, F. M. A.; Almeida, R. A.; Souza, A. D. L.; Medeiros, L. S.; Rodrigues-Filho, E.; Souza, A. Q. L.; Quim. Nova 2012, 35, 771.

18. Kozlovsky, A. G.; Zhelifonova, V. P.; Antipova, T. V.; J. Org. Biomol. Chem. 2013, 1, 11.

19. Nielsen, K. F.; Smedsgaard, J.; J. Chromatogr. A 2003, 1002, 111.

20. Castrillo, J. I.; Hayes, A.; Mohammed, S.; Gaskell, S. J.; Oliver, S. G.; Phytochemistry 2003, 62, 929.

21. Bastos, L. M.; da Silva, F. M. A.; de Souza, L. R. S.; Sá, I. S. C.; Mesquita, R. S.; de Souza, A. D. L.; Nunomura, R. C. S.; J. Braz. Chem. Soc. 2020, 31, 351.

22. Silva, F. M. A.; Silva Filho, F. A.; Lima, B. R.; Almeida, R. A.; Soares, E. R.; Koolen, H. H. F.; Souza, A. D. L.; Pinheiro, M. L. B.; J. Braz. Chem. Soc. 2016, 27, 599.

23. Kim, H. Y.; Park, H. M.; Lee, C. H.; J. Microbiol. Methods 2012, 90, 327.

24. Smedsgaard, J.; J. Chromatogr. A 1997, 760, 264.

25. Souza, A. Q. L.; Souza, A. D. L.; Filho, A. S.; Pinheiro, M. L. B.; Sarquis, M. I. M.; Pereira, J. O.; Acta Amazonica 2004, 34, 185.

26. Nunes, C. A.; Freitas, M. P.; Pinheiro, A. C. M.; Bastos, S. C.; J. Braz. Chem. Soc. 2012, 23, 2003.

27. Tata, A.; Perez, C.; Campos, M. L.; Bayfield, M. A.; Eberlin, M. N.; Ifa, D. R.; Anal. Chem. 2015, 87, 12298.

28. Bauer, J. I.; Gross, M.; Cramer, B.; Wegner, S.; Hausmann, H.; Hamscher, G.; Usleber, E.; Anal. Bioanal. Chem. 2017, 409, 5101.

29. Springer, J. P.; Clardy, J.; Wells, J. M.; Cole, R. J.; Kirksey, J. W.; Tetrahedron Lett. 1975, 30, 2531.

30. Matsui, C.; Ikeda, Y.; Linuma, H.; Kushida, N.; Kunisada, T.; Simizu, S.; Umezawa, K.; J. Antibiot. 2014, 67, 787.

31. Munday-Finch, S. C.; Wilkins, A. L.; Miles, C. O.; Phytochemisty 1996, 41, 327.

32. Houbraken, J.; Frisvad, J. C.; Samson, R.; IMA Fungus 2011, 2,87 .

33. Overy, D. P.; Nielsen, K. F.; Smedsgaard, J.; J. Chem. Ecol. 2005, 31, 2373.

34. Alburae, N. A.; Mohammed, A. E.; Alorfi, H. S.; Turki, A. J.; Asfour, H. Z.; Alarif, W. M.; Abdell-Lateff, A.; Metabolites 2020, 10, 73.

35. Andersen, B.; Frisvad, J. C.; J. Agric. Food Chem. 2004, 52, 7507.

36. Reddy, P.; Guthridge, K.; Vassiliadis, S.; Hemsworth, J.; Hettiarachchige, I.; Spangenberg, G.; Rochfort, S.; Toxins 2019, $11,302$.

37. Sheehan, J. J.; Benedetti, B. L.; Barth, A. L.; Epilepsia 2009 , 50,711 . 
38. Belofsky, G. N.; Gloer, J. B.; Wicklow, D. T.; Dowd, P. F.; Tetrahedron 1995, 51, 3959.

39. Choi, T. Y.; Lee, S. H.; Kim, S. J.; Jo, Y.; Park, C. S.; Choi, S. Y.; Sci. Rep. 2018, 8, 17653.

40. Koizumi, Y.; Arai, M.; Tomoda, H.; Biochim. Biophys. Acta, Mol. Cell Res. 2004, 1693, 47.

41. Kozlovsky, A. G.; Marfenina, O. G.; Vinokurova, N. G.; Zhelifonova, V. P.; Adanin, V. M.; Mycotoxins 1998, 48, 37.

42. Martín, J. F.; Liras, P.; García-Estrada, C. In Biosynthesis and Molecular Genetics of Fungal Secondary Metabolites; Martín, J. F.; García-Estrada, C.; Zeilinger, S., eds.; Fungal Biology Springer: New York, United States of America, 2014, ch. 111.

43. Ali, H.; Ries, M. I.; Nijland, J. G.; Lankhorst, P. P.; Hankemeier, T.; Bovenberg, R. A. L.; Vreeken, R. J.; Driessen, A. J. M.; PLoS One 2013, 8, 65328.
44. Polonsky, J.; Merrien, M. A.; Scott, P. M.; Ann. Nutr. Aliment. 1977, 31, 963.

45. Ohmomo, S.; Sato, T.; Utagawa, T.; Abe, M.; Agric. Biol. Chem. 1975, 39, 1333.

46. Kokkonen, M.; Jestoi, M.; Rizzo, A.; Int. J. Food Microbiol. 2005, 99, 207.

47. Borthwick, A. D.; Costa, N. C.; Crit. Rev. Food Sci. Nutr. 2017, $57,718$.

48. Finoli, C.; Vecchio, A.; Galli, A.; Dragoni, I.; J. Food Prot. 2001, 64, 246.

49. Kopp-Holtwiesche, B.; Rehm, H. J.; J. Environ. Pathol. 1989, $10,41$.

50. Aninat, C.; André, F.; Delaforge, M.; Food Addit. Contam. 2005, 22,361 . 